\title{
SAPC hot topic - A challenge of identity for Academic Primary Care: keeping the whole greater than the sum of its parts
}

\author{
Christine Bond ${ }^{1}$ and Sandra Eldridge ${ }^{2}$ \\ ${ }^{1}$ Head of Centre of Academic Primary Care, Division of Applied Health Sciences, University of Aberdeen, \\ Aberdeen, UK \\ ${ }^{2}$ Professor of Biostatistics, Joint Centre Lead, Director of Pragmatic Clinical Trials Unit, Research Design Service \\ London - Joint Lead for NE Region, Centre for Primary Care and Public Health, Blizard Institute, London, UK
}

What is Academic Primary Care? If you asked a group of primary care academics you would probably get a range of answers, but most would agree it is a distinct discipline. It brings together teachers, researchers, and practitioners from a range of disciplinary backgrounds to promote excellence in the development, delivery, and evaluation of primary care policy and practice (SAPC, 2011). The academic primary care workforce is multidisciplinary, and includes representation of both healthcare professionals who deliver front-line primary care (eg, nurses, physiotherapists, dieticians, pharmacists, doctors) and those with backgrounds in health psychology, sociology, statistics, and generic health services research to name but a few. This breadth of expertise is to be celebrated as it has underpinned the quality research for which primary care is known. However, there are drawbacks.

Although in the clinical context the term 'primary care' is widely understood, with general practitioners and other healthcare disciplines contributing their particular professional expertise to patient care, the reality is that within academia many perceive primary care to be a synonym for general practice. This is possibly not surprising given that the focus of most primary care research is on general practice, that most primary care specific teaching is undergraduate medical teaching, and that SAPC itself evolved from the AUDGP - the

\footnotetext{
Correspondence to: Professor Christine Bond, Head of Centre of Academic Primary Care, Division of Applied Health Sciences, University of Aberdeen, Polwarth West Block, Foresterhill, Aberdeen AB25 2ZD, UK. Email: c.m.bond@abdn. ac.uk
}

(C) Cambridge University Press 2012
Association of University Departments of General Practice in 2001. It is also interesting to reflect why, of all the relevant healthcare disciplines contributing to primary care, medicine is the only one that has created the sub-speciality of Primary Care, supported by a royal college - the Royal College of General Practitioners. Furthermore, general practice itself is unusual in that the clinical speciality, still relatively young in academic terms, is seen by medical peers as being defined by the setting in which it is practiced rather than by a unique set of clinically defined knowledge and skills. These misunderstandings of the clinical discipline have led to issues of identity and sustainability, which have been exacerbated during recent UK-wide University re-structuring into research teams with a focus on clinical topics - for example, cancer or ageing. The inclusion of general practice into clinical academic training schemes, for example, Walport in England and Wales, and SCREDS in Scotland, also has come only relatively recently, and although welcomed, more remains to be done to ensure succession planning of the future workforce.

To further compound the issue of a unique identity for Academic Primary Care, as noted earlier, a significant proportion of those working in Academic Primary Care are non-medical. The heterogeneity of this workforce is particularly challenging. For many non-medical researchers who choose an academic career, there is a prolonged period of continually moving from one contract to the next together with the additional pressure of 'having to ride two horses' - of keeping abreast of developments not only in primary care but also in one's own base discipline; this makes it difficult 
to develop a research focus. There are also limited opportunities to secure core funding as many posts are ringfenced for clinical academics. A notable small minority has achieved independent researcher status with their own niche areas of research and senior academic posts, but in an academic meritocracy this number should be proportionate to overall workforce. There is a need for a formal career structure to complement the training opportunities introduced for clinical colleagues.

These feelings were articulated at the breakfast meeting for non-medical researchers hosted by SAPC at the 2011 Annual Scientific Meeting in Bristol. The meeting was prompted by the SAPC Executive who had identified the current needs of many of their non-medical colleagues and were concerned to address, as far as possible, any concerns identified. A summary of the main points of the meeting has already been reported (Reeve et al., 2011). In the time since then, proposals to support the non-medical primary care workforce have been submitted to, and approved by the SAPC Executive. The proposals include a range of initiatives, one of which is to provide mentoring for the non-medical members of SAPC. A mentoring scheme is now under development and will be launched shortly via the SAPC website (see the non-medical researcher page at www.sapc.ac.uk/index.php/supporting-apc/ multidisciplinary-researchers) and mail shots.

Mentoring is a term that covers a broad range of activities. It can be formal or informal, and can have different purposes. It is also often confused with 'coaching'. However, although both coaching and mentoring share similar approaches and depend on a common set of skills, generally coaching is regarded as a short-term process, and mentoring depends on a longer lasting relationship between mentor and mentee. Mentoring has been described as 'a process for the informal transfer of knowledge, social capital and psychological support ... usually face to face and during a sustained period of time, between a person perceived to have greater relevant knowledge, wisdom or experience and a person ... perceived to have less' (Bozeman and Feeney, 2007: 731). One of the key aspects of mentoring is that the mentor does not have a remit to be prescriptive about what the mentee should do, but helps the mentee to develop as a person so that they can themselves come to decisions. There are mutual benefits in the mentor-mentee relationship. Although the mentor gains satisfaction from sharing leadership 'giving back and being refreshed about their own work' the mentee 'integrates better with the organisation and gets experience and advice' (Posner and Kouzes, 1993: 155).

Although some people may be natural mentors most potential mentors benefit from some training in key aspects of how to approach their role. The proposed SAPC initiative will provide training for 10 non-medical mentors in the first year; each trained mentor will have to commit to mentoring two or more junior non-medical SAPC members during that year. The scheme will be evaluated after one year to assess its impact on individual mentor and mentee, with a focus on identity and career development. The scheme will be revised in the light of feedback and delivered again in the following year. Thus, SAPC hope to build a network of mentor-mentees to the benefit of the non-medical academic primary care workforce in particular and thus for Academic Primary Care in general. Mentoring should lead to better retention of our multidisciplinary academic primary care workforce (Pompper and Adams, 2006).

In summary, we have a responsibility to ensure appropriate career development support for all those engaged in Academic Primary Care, and such support must recognise the different challenges for different subgroups. This article has provided an example of one initiative for non-medical colleagues. If successful SAPC will be asked to reflect on whether or not it would be beneficial to extend it to all their members, medical and non-medical. Retaining a rich diversity of both medical and nonmedical primary care researchers and teachers is key to the continued success of primary care, and to helping the United Kingdom continue to lead the agenda for Academic Primary Care (Sullivan et al., 2009). Together we are much stronger than any of our individual disciplines on their own.

\section{References}

Bozeman, B. and Feeney, M.K. 2007: Toward a useful theory of mentoring: a conceptual analysis and critique. Administration \& Society 39, 719-39.

Pompper, D. and Adams, J. 2006: Under the microscope: gender and mentor-protege relationships. Public Relations Review 32, 309-15. 
Posner, B. and Kouzes, J. 1993: Credibility. San Francisco: Jossey Bass, $155 \mathrm{pp}$.

Reeve, J., Abholz, H., Bailey, T., Bates, E., Bond, C., Chauhan, U., Eldridge, S., Irving, G., Keong, D., Mughal, F., Nicum, S., Singh, S., Taylor, C., and Younie, L. 2011: A pause for thought: reflections on the 2011 SAPC Annual Conference. Primary Health Care Research \& Development 12, 393-94.
SAPC. 2011: The Society for Academic Primary Care: position statement April 2011. Primary Health Care Research \& Development 12, 183-84.

Sullivan, F., Hinds, A., and Wallace, P. 2009: UK Primary Care Research portfolio review. Retrieved 6 July 2012 from www.sspc.ac.uk/documents/final_port_review.pdf 